\title{
Low lymphocyte count and high monocyte count predicts poor prognosis of gastric cancer
}

Fan Feng ${ }^{1 \dagger}$, Gaozan Zheng ${ }^{1 \dagger}$, Qiao Wang ${ }^{1,2 \dagger}$, Shushang Liu', Zhen Liu', Guanghui Xu', Fei Wang ${ }^{1,3}$, Man Guo Xiao Lian ${ }^{1}$ and Hongwei Zhang ${ }^{1 *}$ (1)

\begin{abstract}
Background: Existing data about the prognostic value of absolute count of blood cells in gastric cancer was limited. Thus, the present study aims to investigate the prognostic value of absolute count of white blood cell (WBC), neutrophil, lymphocyte, monocyte and platelet in gastric cancer patients.

Methods: From September 2008 to March 2015, 3243 patients treated with radical gastrectomy were enrolled in the present study. Clinicopathological characteristics were recorded. The prognostic value of blood test in gastric cancer patients were analyzed.

Results: There were 2538 male and 705 female. The median age was 58 years (range 20-90). The median follow-up time was 24.9 months (range 1-75). The 1-, 3- and 5-year overall survival rate was $88.9 \%, 65.8 \%$ and $57.2 \%$, respectively. The optimal cut off value was $6.19 \times 109 / \mathrm{L}$ for WBC $(P=0.146), 4.19 \times 109 / \mathrm{L}$ for neutrophil $(P=0.004), 1.72 \times 109 / \mathrm{L}$ for lymphocyte $(P=0.000), 0.51 \times 109 / \mathrm{L}$ for monocyte $(P=0.019)$ and $260.0 \times 109 / \mathrm{L}$ for platelet $(P=0.002)$, respectively. Neutrophil, lymphocyte, monocyte and platelet were risk factors for the prognosis of gastric cancer (all $P<0.05)$. However, only lymphocyte and monocyte were independent risk factors (both $P<0.05$ ). Combination of lymphocyte and monocyte could increase the prognostic value for gastric cancer patients, especially in stage II/III gastric cancer patients.

Conclusions: High absolute count of neutrophil, monocyte and platelet, and low absolute count of lymphocyte were associated with poor prognosis of gastric cancer. However, only lymphocyte and monocyte count were independent prognostic predictors. Combination of lymphocyte and monocyte count could further increase the predictive value for gastric cancer.
\end{abstract}

Keywords: Gastric cancer, Lymphocyte, Monocyte, Prognosis

\section{Background}

Up to date, the prognosis and treatment of gastric cancer patients after radical gastrectomy mainly depends on TNM stage system. However, the prognosis of gastric cancer patients could be various even with the same tumor stage. Thus, additional parameters need to be defined to better evaluate the prognosis of patients.

\footnotetext{
* Correspondence: zhanghwfmmu@126.com

${ }^{\dagger}$ Fan Feng, Gaozan Zheng and Qiao Wang contributed equally to this work.

'Division of Digestive Surgery, Xijing Hospital of Digestive Diseases, Fourth Military Medical University, 127 West Changle Road, Xi'an 710032, Shaanxi, China

Full list of author information is available at the end of the article
}

Over the past decades, prognostic value of blood test parameters in gastric cancer patients has been investigated by numerous studies $[1,2]$. Because blood test is simple, convenient, reproducible and cost-effective. However, the most common parameters been investigated in the previous reports were neutrophil-to-lymphocyte ratio (NLR) and platelet-to-lymphocyte ratio (PLR) [3, 4]. As NLR and PLR could effectively reflect the inflammation and immune status in vivo, which have been demonstrated to be associated with the progression and prognosis of tumors. However, the prognostic value of absolute count of blood cells, which was more convenient, has rarely been investigated in gastric cancer patients.

(C) The Author(s). 2018 Open Access This article is distributed under the terms of the Creative Commons Attribution 4.0 International License (http://creativecommons.org/licenses/by/4.0/), which permits unrestricted use, distribution, and 
Given this situation, the present study aims to investigate the prognostic value of absolute count of WBC, neutrophil, lymphocyte, monocyte and platelet in gastric cancer patients.

\section{Methods}

This study was performed in the Division of Digestive Surgery, Xijing Hospital of Digestive Diseases. From September 2008 to March 2015, a total of 3243 gastric cancer patients was enrolled in the present study. All patients were treated with radical D2 gastrectomy and regular follow up. This study was approved by the Ethics Committee of Xijing Hospital, and written informed consent was obtained from all patients before surgery.

Preoperative blood test was performed within 7 days before surgery. Absolute count of WBC, neutrophil, lymphocyte, monocyte and platelet were recorded. Patients with signs of infection were excluded. Clinicopathological data including gender, age, tumor location, tumor size, pathological type, tumor depth, lymph node metastasis and tumor stage were collected. The patients were followed up till November 2015 every 3 months.

Data were processed using SPSS 22.0 for Windows (SPSS Inc., Chicago, IL, USA). The best cut off value of absolute count of WBC, neutrophil, lymphocyte, monocyte and platelet for the prognosis of gastric cancer were calculated using X-tile software. X-tile is a statistical software cut-point selection. The X-tile software allows the user to move a cursor across the grid and provides an "on-the-fly" histogram of the resulting population subsets along with an associated Kaplan-Meier curve [5]. Risk factors for the prognosis of gastric cancer identified by univariate analysis were further assessed by multivariate analysis using the Cox's proportional hazards regression model. Overall survival was analyzed by Kaplan-Meier method. The $P$ value was considered to be statistically significant at $5 \%$ level.

\section{Results}

The clinicopathological characteristics of the entire cohort was summarized in Table 1 . There were 2538 male and 705 female. The median age was 58 years (range 20-90). The median follow-up time was 24.9 months (range 175 ). The 1-, 3- and 5-year overall survival rate was $88.9 \%$, $65.8 \%$ and $57.2 \%$, respectively.

The optimal cut off value of absolute count of WBC, neutrophil, lymphocyte, monocyte and platelet for the prognosis of gastric cancer patients were shown in Fig. 1. The optimal cut off value was $6.19 \times 10^{9} / \mathrm{L}$ for WBC $(P=0.146), \quad 4.19 \times 10^{9} / \mathrm{L}$ for neutrophil $(P=0.004)$, $1.72 \times 10^{9} / \mathrm{L}$ for lymphocyte $(P=0.000), 0.51 \times 10^{9} / \mathrm{L}$ for monocyte $(P=0.019)$ and $260.0 \times 10^{9} / \mathrm{L}$ for platelet $(P=0.002)$, respectively.
Table 1 Clinicopathological characteristics of patients

\begin{tabular}{|c|c|}
\hline Characteristics & $n=3243$ \\
\hline \multicolumn{2}{|l|}{ Gender } \\
\hline Male & 2538 \\
\hline Female & 705 \\
\hline \multicolumn{2}{|l|}{ Age } \\
\hline$\leq 60$ & 1930 \\
\hline$>60$ & 1313 \\
\hline \multicolumn{2}{|l|}{ Tumor location } \\
\hline Upper third & 1022 \\
\hline Middle third & 531 \\
\hline Lower third & 1429 \\
\hline Entire & 261 \\
\hline \multicolumn{2}{|l|}{ Tumor size (cm) } \\
\hline$\leq 5$ & 2248 \\
\hline$>5$ & 995 \\
\hline \multicolumn{2}{|l|}{ Pathological type } \\
\hline Well differentiated & 365 \\
\hline Moderately differentiated & 827 \\
\hline Poorly differentiated & 1866 \\
\hline Signet ring cell or Mucinous & 185 \\
\hline \multicolumn{2}{|l|}{ Tumor depth } \\
\hline $\mathrm{T} 1$ & 603 \\
\hline $\mathrm{T} 2$ & 499 \\
\hline T3 & 1165 \\
\hline T4 & 976 \\
\hline \multicolumn{2}{|l|}{ Lymph node metastasis } \\
\hline NO & 1162 \\
\hline $\mathrm{N} 1$ & 623 \\
\hline N2 & 562 \\
\hline N3 & 896 \\
\hline \multicolumn{2}{|l|}{ Tumor stage } \\
\hline । & 801 \\
\hline$\|$ & 946 \\
\hline III & 1496 \\
\hline WBC $\left(10^{9} / L\right)$ & $5.82 \pm 1.47$ \\
\hline Neutrophil $\left(10^{9} / \mathrm{L}\right)$ & $3.62 \pm 1.29$ \\
\hline Lymphocyte $\left(10^{9} / L\right)$ & $1.68 \pm 0.56$ \\
\hline Monocyte $\left(10^{9} / \mathrm{L}\right)$ & $0.39 \pm 0.16$ \\
\hline Platelet $\left(10^{9} / \mathrm{L}\right)$ & $215.81 \pm 77.53$ \\
\hline
\end{tabular}

The univariate analysis showed that age, tumor size, pathological type, tumor depth, lymph node metastasis, tumor stage, neutrophil, lymphocyte, monocyte and platelet were risk factors for the prognosis of gastric cancer (Table 2). The overall survival of gastric cancer patients according to neutrophil, lymphocyte, monocyte and platelet 


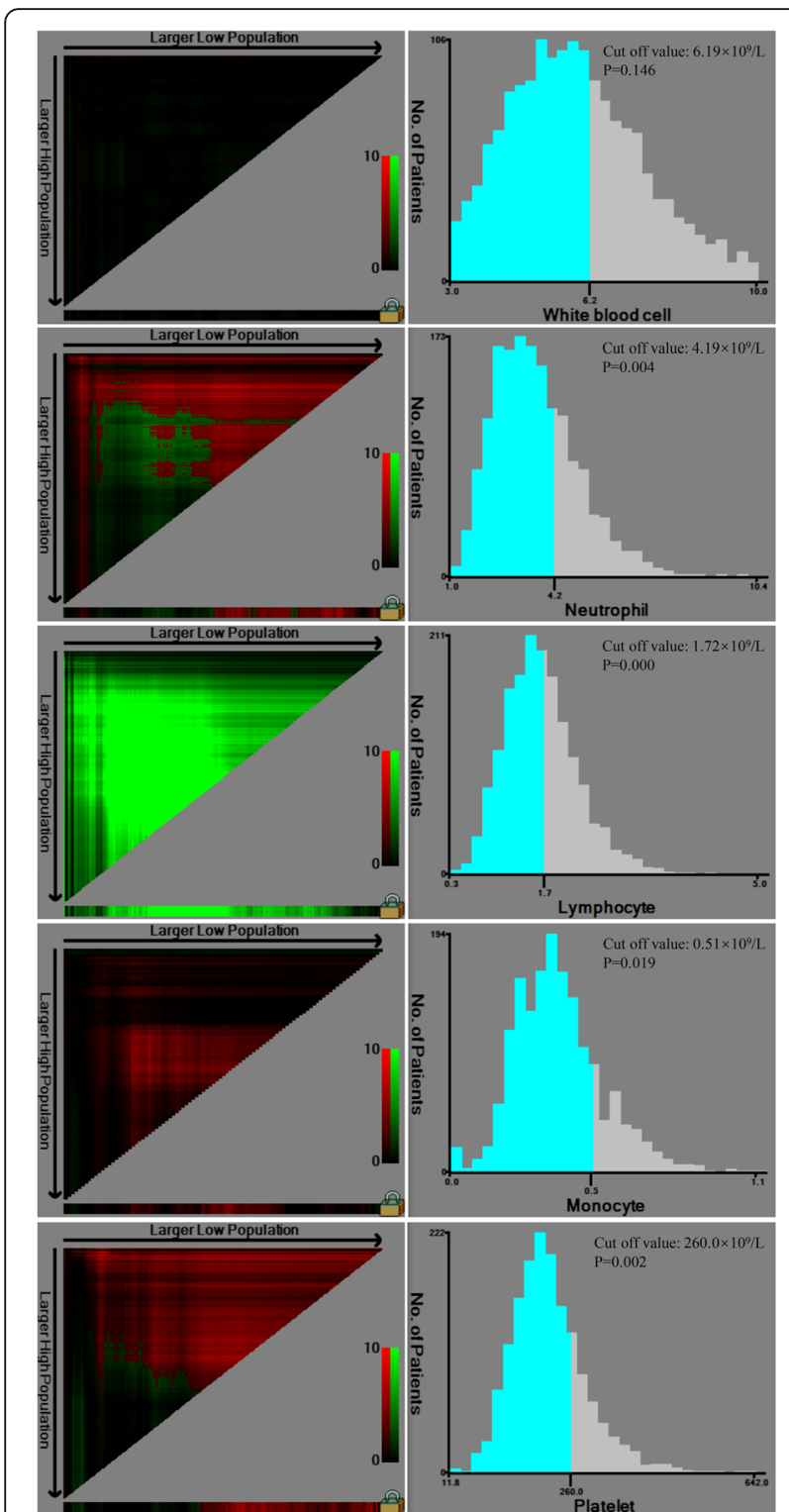

Fig. 1 Calculation of cut off value of WBC, neutrophil, lymphocyte, monocyte and platelet count by X-tile software

were shown in Fig. 2. However, only age, tumor size, tumor depth, lymph node metastasis, lymphocyte and monocyte were independent risk factors for the prognosis of gastric cancer (Table 2). Then, the prognostic value of lymphocyte and monocyte were analyzed stratified by TNM stage. The results showed that both lymphocyte and monocyte could predict the prognosis of stage II/III gastric cancer patients (Fig. 3).

Further, the prognostic value of combination of lymphocyte and monocyte for gastric cancer patients were evaluated. Patients were divided into three groups according to the levels of lymphocyte and monocyte: Group 1: patients with high lymphocyte and low monocyte; Group 2: patients with high lymphocyte and high monocyte, or low lymphocyte and low monocyte; Group 3: patients with low lymphocyte and high monocyte. As the prognosis of patients with high lymphocyte and high monocyte and that with low lymphocyte and low monocyte were comparable, these patients were all assigned to group 2. The overall survival of the three groups were shown in Fig. 4. The results showed that combination of lymphocyte and monocyte count could increase the predictive value for the prognosis of the entire cohort. Moreover, we found that combination of lymphocyte and monocyte count could only predict the prognosis of stage II/III gastric cancer patients, but not stage I gastric cancer patients.

\section{Discussion}

Most studies focused on the prognostic value of NLR and PLR in gastric cancer patients. Full analysis of the prognostic value of absolute count of blood cells in gastric cancer was lacking. Therefore, the present study investigated the prognostic value of absolute count of WBC, neutrophil, lymphocyte, monocyte and platelet in gastric cancer patients. We found that high absolute count of neutrophil, monocyte and platelet and low absolute count of lymphocyte were associated with poor prognosis of gastric cancer. However, only lymphocyte and monocyte count were independent prognostic predictors. Moreover, combination of lymphocyte and monocyte count could further increase the predictive value for the prognosis of stage II/III gastric cancer patients but not stage I patients.

Eo et al. reported that absolute lymphocyte count and monocyte count were associated with the disease-free survival and overall survival of gastric cancer patients [6]. However, the two parameters were not independent prognostic factors. This may attribute to the relatively small sample size in the study. In a study containing 250 cases of surgically treated gastric cancer patients, Heras et al. found that increase of platelet count was correlated with tumor progression and unfavorable prognosis of gastric cancer [7]. Zhang et al. also reported that elevated platelet count was associated with poor prognosis in patients with gastric cancer [1]. In our present study, which contained a relatively large sample size of 3243 cases, neutrophil, lymphocyte, monocyte and platelet were all associated with prognosis of gastric cancer patients, and lymphocyte and monocyte were independent risk factors.

Neutrophil is one of the inflammatory markers [8]. Neutrophils could promote growth and metastasis of tumors through secreting a variety of cytokines, including matrix metalloproteinase-9 [9], chemokines [10] and vascular endothelial growth factor (VEGF) [11]. It was reported that neutrophils could promote adhesion between circulating tumor cells and distant target organs through acting as an adhesive adapter, finally increasing the chance of distant metastasis [12]. Moreover, neutrophil could also inhibit the 
Table 2 Univariate and multivariate analysis of risk factors for prognosis of gastric cancer patients

\begin{tabular}{|c|c|c|c|c|c|c|}
\hline \multirow[t]{2}{*}{ Prognostic factors } & \multicolumn{3}{|c|}{ Univariate } & \multicolumn{3}{|c|}{ Multivariate } \\
\hline & $\beta$ & HR $(95 \% \mathrm{Cl})$ & $P$ & $\beta$ & HR $(95 \%$ Cl) & $P$ \\
\hline Gender & 0.072 & $1.075(0.922-1.253)$ & 0.354 & & & \\
\hline Age & 0.258 & $1.294(1.139-1.470)$ & 0.000 & 0.258 & $1.295(1.137-1.474)$ & 0.000 \\
\hline Tumor location & -0.030 & 0.971 (0.910-1.035) & 0.363 & & & \\
\hline Tumor size & 1.105 & $3.020(2.656-3.433)$ & 0.000 & 0.410 & $1.507(1.313-1.731)$ & 0.000 \\
\hline Pathological type & 0.433 & $1.541(1.414-1.681)$ & 0.000 & 0.093 & $1.098(0.996-1.210)$ & 0.060 \\
\hline Tumor depth & 0.795 & $2.214(2.043-2.398)$ & 0.000 & 0.440 & $1.553(1.416-1.703)$ & 0.000 \\
\hline Lymph node metastasis & 0.710 & $2.034(1.917-2.159)$ & 0.000 & 0.503 & $1.653(1.544-1.770)$ & 0.000 \\
\hline Tumor stage & 1.239 & $3.452(3.082-3.867)$ & 0.000 & & & \\
\hline White blood cell & 0.098 & $1.102(0.966-1.258)$ & 0.146 & & & \\
\hline Neutrophil & 0.205 & $1.227(1.068-1.409)$ & 0.004 & 0.038 & $1.038(0.897-1.202)$ & 0.613 \\
\hline Lymphocyte & -0.433 & $0.648(0.567-0.741)$ & 0.000 & -0.254 & $0.776(0.677-0.888)$ & 0.000 \\
\hline Monocyte & 0.173 & $1.189(1.029-1.374)$ & 0.019 & 0.257 & $1.293(1.111-1.505)$ & 0.001 \\
\hline Platelet & 0.232 & $1.262(1.091-1.459)$ & 0.002 & -0.096 & $0.908(0.781-1.056)$ & 0.211 \\
\hline
\end{tabular}

antitumor immune function of natural killer cells and cytotoxic T cells [13].

Lymphocyte plays prominent role in the tumor related immunology. It possesses potent antitumor immune function that could inhibit progression of several tumors [14], and elevated level of lymphocyte was reported to be associated with favorable prognosis of a variety of tumors [15]. It was also reported that several subtypes of tumor infiltrating lymphocyte were associated with better outcomes of a variety of tumors [16-18], including CD8+ $\mathrm{T}$ cells [19] and memory $\mathrm{T}$ cells [20]. However, some subsets of $\mathrm{T}$ cells were associated with progression and unfavorable prognosis of tumors, such as regulatory $\mathrm{T}$ cells [21] and Th17 cells [22]. Although different subset of $\mathrm{T}$ cells was associated with adverse prognosis of tumors, high level of absolute lymphocyte count was demonstrated to be associated with favorable prognosis of gastric cancer patients in our present study.

Elevated monocyte was reported to be associated with the poor prognosis of a variety of tumor, including prostate cancer [23], cervical cancer [24] and hepatocellular carcinoma [25]. Monocyte could promote tumorigenesis

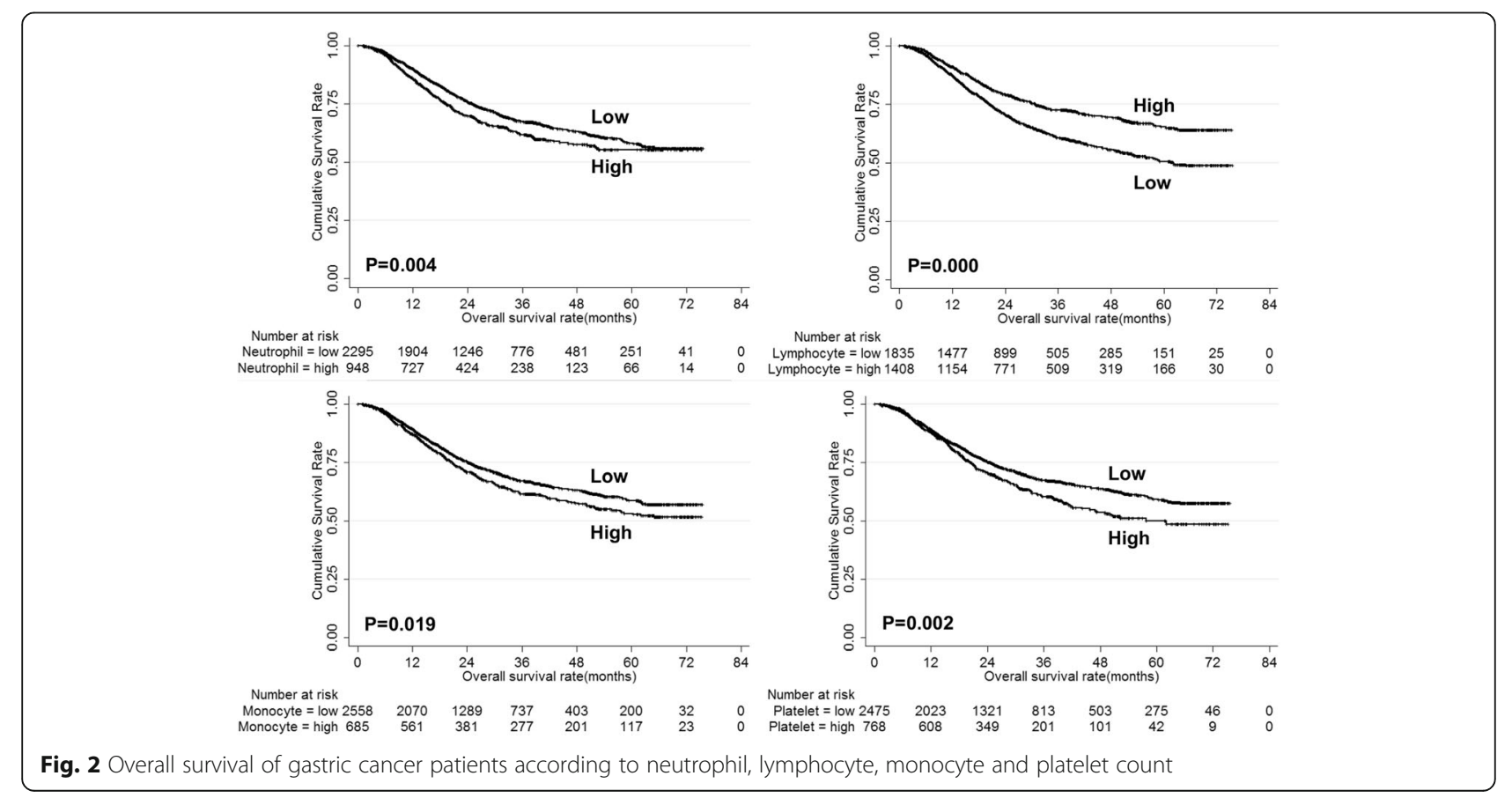




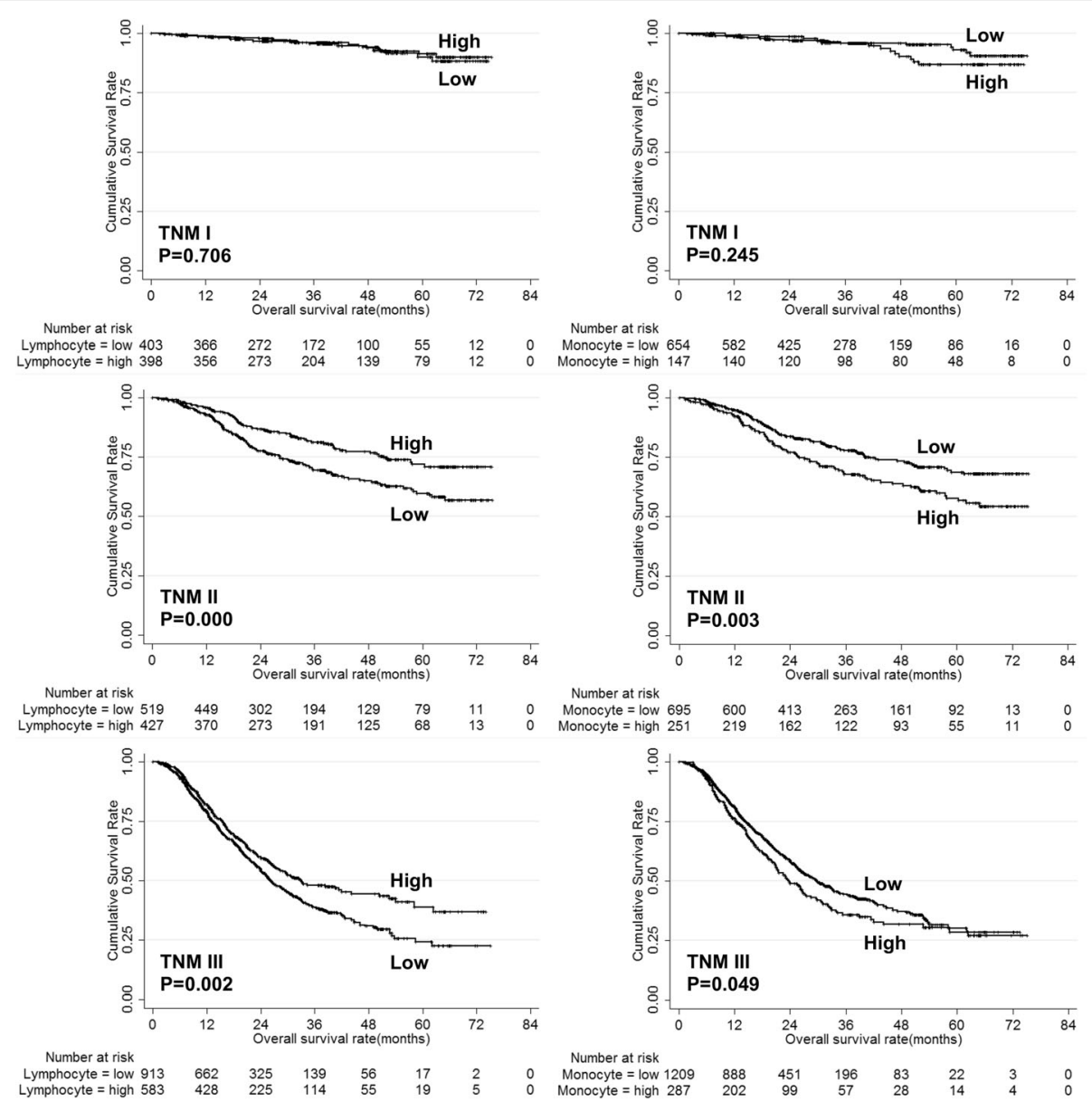

Fig. 3 Overall survival according to lymphocyte and monocyte count stratified by TNM stage

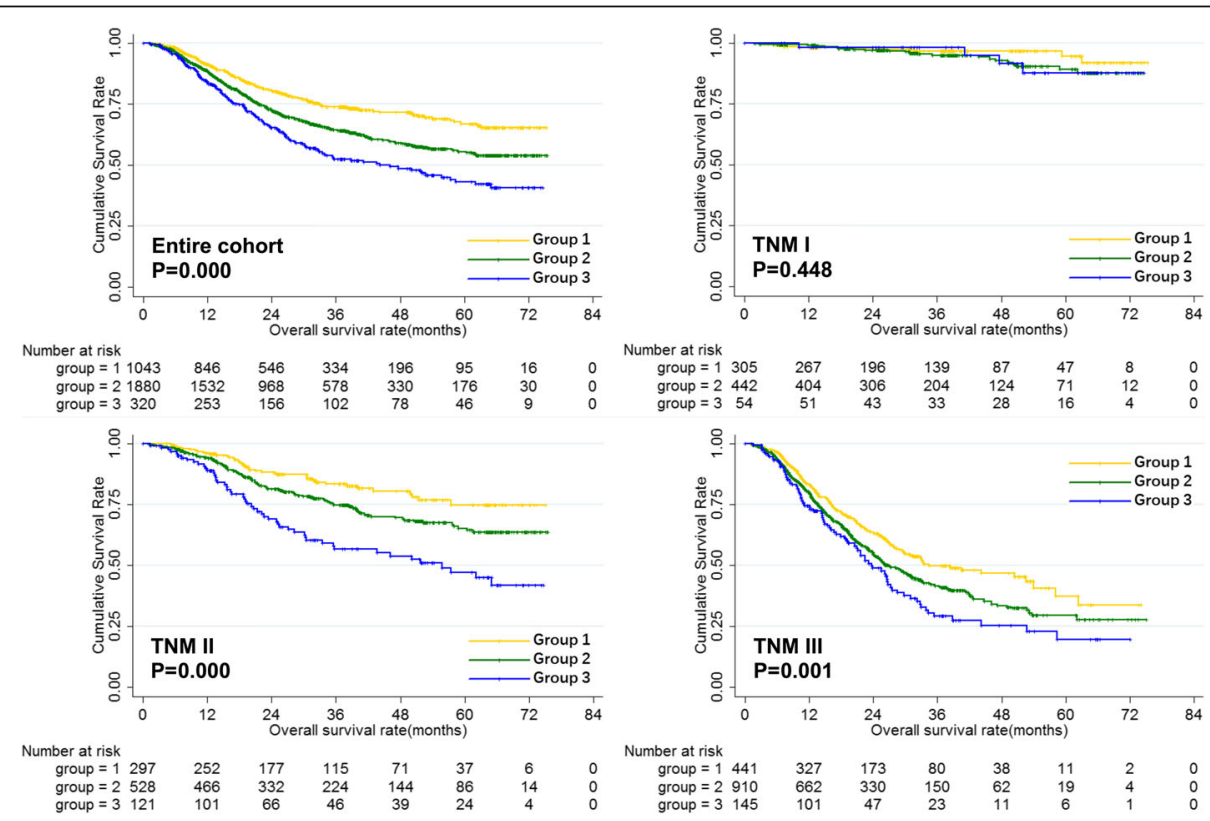

Fig. 4 Overall survival of gastric cancer patients according to the combination of lymphocyte and monocyte count 
and angiogenesis, and could also inhibit the antitumor immune response in vivo [26]. Moreover, monocytes could differentiate into tumor associated macrophages (TAM) by tumor microenvironment [27]. TAM could promote tumor angiogenesis and tumor growth through secretion of tumor necrosis factor alpha [28] and VEGF [29]. TAM could also facilitate invasion and migration of tumor cells through secreting various proteases and protease activators which could degrade extracellular matrix [29].

Platelet also plays prominent role in the tumor related inflammation [30] and thrombocytosis has been reported to be associated with poor prognosis in gastric cancer patients [7]. It is accepted that tumor cells could be damaged by mechanical trauma and shear force when passing through the microvasculature, and by the immune system in the blood stream. However, platelet could protect tumor cells against these damages through covering tumor cells [31]. Platelet could promote tumor growth by increasing angiogenesis via VEGF [32], and the association between serum VEGF level and platelet count has been demonstrated [33].

There were several limitations in the present study. Firstly, it was a retrospective analysis with relatively limited sample size. Multi-center studies are needed to verify the prognostic value of these blood cells. Secondly, the cut off value could be calculated through different methods, including median value, receiver operating characteristic curve and X-tile software. The prognostic value of blood cells based on different cut off values through different methods were not compared. Thirdly, the prognostic value of blood cells after surgery was not evaluated. Fourthly, data about recurrence were not available. As a result, the correlation between blood cell count and disease-free survival were not analyzed. Fifthly, blood cell count could not predict the prognosis of stage I gastric cancer patients in our study. The reasons were not deeply discussed. One of the reasons may be that the sample size of stage I patients was not large enough and the follow-up time was relatively short.

\section{Conclusions}

Absolute count of blood cells was more convenient in predicting the prognosis of gastric cancer patients. High absolute count of neutrophil, monocyte and platelet, and low absolute count of lymphocyte were associated with poor prognosis of gastric cancer. However, only lymphocyte and monocyte count were independent prognostic predictors. Combination of lymphocyte and monocyte count could further increase the predictive value for gastric cancer.

\section{Abbreviations}

NLR: Neutrophil-to-lymphocyte ratio; PLR: Platelet-to-lymphocyte ratio; TAM: Tumor associated macrophages; VEGF: Vascular endothelial growth factor; WBC: White blood cell

\section{Funding}

This study was supported in part by grants from the National Natural Scientific Foundation of China [NO. 31100643, 31570907, 81300301, 81572306, 81502403, XJZT12Z03].

\section{Availability of data and materials}

The datasets used and/or analysed during the current study are available from the corresponding author on reasonable request.

\section{Authors' contributions}

FF, GZ, and QW conceived the study and drafted the manuscript. SL, QW, ZL, GX, FW collected the data. MG and XL performed statistical analysis. HZ designed and supervised the study. All authors read and approved the final manuscript.

\section{Ethics approval and consent to participate}

This study was approved by the Ethics Committee of Xijing Hospital, and written informed consent was obtained from the patients in our center.

\section{Consent for publication}

Not Applicable.

\section{Competing interests}

The authors declare that they have no competing interests.

\section{Publisher's Note}

Springer Nature remains neutral with regard to jurisdictional claims in published maps and institutional affiliations.

\section{Author details}

${ }^{1}$ Division of Digestive Surgery, Xijing Hospital of Digestive Diseases, Fourth Military Medical University, 127 West Changle Road, Xi'an 710032, Shaanxi, China. ${ }^{2}$ Department of General Surgery, No. 91 Hospital of PLA, Jiaozuo 454000, Henan, China. ${ }^{3}$ Department of General Surgery, No. 534 Hospital of PLA, Luoyang 471000, Henan, China.

Received: 17 April 2018 Accepted: 27 September 2018

Published online: 11 October 2018

\section{References}

1. Zhang XJ, Liu YG, Shi XJ, Chen XW, Zhou D, Zhu DJ. The prognostic role of neutrophils to lymphocytes ratio and platelet count in gastric cancer: a meta-analysis. Int J Surg. 2015;21:84-91.

2. Ma JY, Liu Q. Clinicopathological and prognostic significance of lymphocyte to monocyte ratio in patients with gastric cancer: a meta-analysis. Int J Surg. 2018;50:67-71

3. Szor DJ, Dias AR, Pereira MA, Ramos MFKP, Zilberstein B, Cecconello I, et al. Prognostic role of neutrophil/lymphocyte ratio in resected gastric Cancer: a systematic review and meta-analysis. Clinics (Sao Paulo). 2018;73:e360.

4. Xu Z, Xu W, Cheng H, Shen W, Ying J, Cheng F, et al. The prognostic role of the platelet-lymphocytes ratio in gastric Cancer: a meta-analysis. PLoS One. 2016;11(9):e0163719

5. Camp RL, Dolled-Filhart M, Rimm DL. X-tile: a new bio-informatics tool for biomarker assessment and outcome-based cut-point optimization. Clin Cancer Res. 2004;10(21):7252-9.

6. Eo WK, Jeong DW, Chang HJ, et al. Absolute monocyte and lymphocyte count prognostic score for patients with gastric cancer. World J Gastroenterol. 2015;21(9):2668-76.

7. Heras P, Hatzopoulos A, Kritikos N, Kritikos K. Platelet count and tumor progression in gastric cancer patients. Scand J Gastroenterol. 2010;45(7-8): 1005-6.

8. Rosales C. Neutrophil: a cell with many roles in inflammation or several cell types? Front Physiol. 2018;9:113.

9. Bausch D, Pausch T, Krauss T, et al. Neutrophil granulocyte derived MMP-9 is a VEGF independent functional component of the angiogenic switch in pancreatic ductal adenocarcinoma. Angiogenesis. 2011;14(3):235-43.

10. Tecchio C, Cassatella MA. Neutrophil-derived chemokines on the road to immunity. Semin Immunol. 2016;28(2):119-28.

11. Tan KW, Chong SZ, Wong FH, et al. Neutrophils contribute to inflammatory lymphangiogenesis by increasing VEGF-A bioavailability and secreting VEGFD. Blood. 2013;122(22):3666-77. 
12. Spicer JD, MCDonald B, Cools-Lartigue JJ, et al. Neutrophils promote liver metastasis via mac-1-mediated interactions with circulating tumor cells. Cancer Res. 2012;72(16):3919-27.

13. Shau HY, Kim A. Suppression of lymphokine-activated killer induction by neutrophils. J Immunol. 1988;141(12):4395-402.

14. Wang SC, Chou JF, Strong VE, Brennan MF, Capanu M, Coit DG. Pretreatment neutrophil to lymphocyte ratio independently predicts disease-specific survival in Resectable gastroesophageal junction and gastric adenocarcinoma. Ann Surg. 2016;263(2):292-7.

15. Quigley DA, Kristensen V. Predicting prognosis and therapeutic response from interactions between lymphocytes and tumor cells. Mol Oncol. 2015;9(10):2054-62.

16. Eriksen AC, Sørensen FB, Lindebjerg J, Hager $H$, de Pont Christensen R, KiærFrifeldt $\mathrm{S}$, et al. The prognostic value of tumor-infiltrating lymphocytes in stage II Colon Cancer. A Nationwide population-based study. Transl Oncol. 2018;11(4):979-87.

17. Toss MS, Miligy I, Al-Kawaz A, Alsleem M, Khout H, Rida PC, et al. Prognostic significance of tumor-infiltrating lymphocytes in ductal carcinoma in situ of the breast. Mod Pathol. 2018;31(8):1226-36.

18. Zhou C, Wu Y, Jiang L, Li Z, Diao P, Wang D, et al. Density and location of CD3+ and CD8+ tumor-infiltrating lymphocytes correlate with prognosis of oral squamous cell carcinoma. J Oral Pathol Med. 2018:47(4):359-67.

19. Miura T, Yoshizawa T, Hirai H, Seino H, Morohashi S, Wu Y, et al. Prognostic impact of CD163+ macrophages in tumor stroma and CD8+ T-cells in Cancer cell nests in invasive extrahepatic bile duct Cancer. Anticancer Res. 2017:37(1):183-90

20. Djenidi F, Adam J, Goubar A, Durgeau A, Meurice G, de Montpréville V, et al. CD8+CD103+ tumor-infiltrating lymphocytes are tumor-specific tissueresident memory $\mathrm{T}$ cells and a prognostic factor for survival in lung cancer patients. J Immunol. 2015;194(7):3475-86.

21. Shitara K, Nishikawa H. Regulatory T cells: a potential target in cancer immunotherapy. Ann N Y Acad Sci. 2018;1417(1):104-15.

22. lida T, Iwahashi M, Katsuda M, et al. Tumor-infiltrating CD4+ Th17 cells produce IL-17 in tumor microenvironment and promote tumor progression in human gastric cancer. Oncol Rep. 2011;25(5):1271-7.

23. Shigeta K, Kosaka T, Kitano S, Yasumizu Y, Miyazaki Y, Mizuno R, et al. High absolute monocyte count predicts poor clinical outcome in patients with castration-resistant prostate Cancer treated with docetaxel chemotherapy. Ann Surg Oncol. 2016;23(12):4115-22.

24. Lee YY, Choi $\mathrm{CH}$, Sung $\mathrm{CO}$, et al. Prognostic value of pre-treatment circulating monocyte count in patients with cervical cancer: comparison with SCC-ag level. Gynecol Oncol. 2012;124(1):92-7.

25. Sasaki A, Iwashita Y, Shibata K, Matsumoto T, Ohta M, Kitano S. Prognostic value of preoperative peripheral blood monocyte count in patients with hepatocellular carcinoma. Surgery. 2006;139(6):755-64.

26. Gabrilovich DI, Nagaraj S. Myeloid-derived suppressor cells as regulators of the immune system. Nat Rev Immunol. 2009;9(3):162-74.

27. Petty AJ, Yang Y. Tumor-associated macrophages: implications in cancer immunotherapy. Immunotherapy. 2017;9(3):289-302.

28. Yang L, Zhang Y. Tumor-associated macrophages: from basic research to clinical application. J Hematol Oncol. 2017;10(1):58.

29. Sawa-Wejksza K, Kandefer-Szerszeń M. Tumor-associated macrophages as target for antitumor therapy. Arch Immunol Ther Exp. 2018;66(2):97-111.

30. Schreiber RD, Old LJ, Smyth MJ. Cancer immunoediting: integrating immunity's roles in cancer suppression and promotion. Science. 2011;331(6024):1565-70.

31. Shou LM, Zhang QY, Li W, et al. Cantharidin and norcantharidin inhibit the ability of MCF-7 cells to adhere to platelets via protein kinase C pathwaydependent downregulation of alpha2 integrin. Oncol Rep. 2013;30(3):1059-66.

32. Zhou X, Du Y, Huang $Z$, et al. Prognostic value of PLR in various cancers: a meta-analysis. PLoS One. 2014;9(6):e101119.

33. Benoy I, Salgado R, Colpaert C, Weytjens R, Vermeulen PB, Dirix LY. Serum interleukin 6, plasma VEGF, serum VEGF, and VEGF platelet load in breast cancer patients. Clin Breast Cancer. 2002;2(4):311-5.

Ready to submit your research? Choose BMC and benefit from:

- fast, convenient online submission

- thorough peer review by experienced researchers in your field

- rapid publication on acceptance

- support for research data, including large and complex data types

- gold Open Access which fosters wider collaboration and increased citations

- maximum visibility for your research: over $100 \mathrm{M}$ website views per year

At $\mathrm{BMC}$, research is always in progress.

Learn more biomedcentral.com/submissions 